\title{
Use of antibiotics among non-medical students in a Nigerian university
}

\author{
Sanya TE, *Titilayo OF, Adisa R, Segun JS \\ Department of Clinical Pharmacy \& Pharmacy Administration, University of Ibadan, Nigeria
}

\begin{abstract}
Background: Antibiotic misuse is a major contributory factor to treatment failure, antibiotic resistance and high healthcare costs.

Objectives: To evaluate level of self-reported antibiotic misuse among non-medical undergraduate students of a Nigerian university.

Methods: Respondents' knowledge of antibiotics and disposal system for left-over antibiotics were explored using a structured questionnaire. Data were summarized with descriptive statistics. Chi square was used to evaluate relationship between specific categorical variables and respondents' opinions with $\mathrm{p}<0.05$.

Results: More than half the respondents obtained their antibiotics through doctor's prescriptions $(273 ; 68.3 \%)$. The study revealed gross antibiotic misuse with majority, $(298 ; 74.5 \%)$ either by keeping left-over antibiotics for future use or throwing it away with refuse. Respondents $(289 ; 72.3 \%)$ sometimes forgot to take the antibiotics. Financial constraints $(73 ; 18.3 \%)$, long duration of treatment $(70 ; 17.5 \%)$, side effects experienced $(60 ; 15.0 \%)$, polypharmacy $(56 ; 14.0 \%)$, tablet size $(45 ; 11.3 \%)$, and perceived low level of confidence in the prescriber $(11 ; 2.8 \%)$ were major reasons for non-adherence. Course of study of respondents had no significant effect on respondents' knowledge or adherence ( $p>0.05)$.

Conclusion: Misuse of antibiotics among non-medical undergraduate students in a Nigerian university setting is pervasive suggesting an urgent need for enlightenment on rational use and disposal of antibiotics.

Key words: Antibiotic misuse, University Students, Nigeria

African Health Sciences 2013; 13(4): 1149 - 1155 http://dx.doi.org/10.4314/ahs.v13i4.41
\end{abstract}

\section{Introduction}

Antibiotic misuse is a global burden which has led to a myriad of problems. The practice that constitutes antibiotic misuse ranges from administration of antibiotics for viral infections, stopping therapy mid-way, saving prescribed antibiotics for future use, to sharing or using someone else's antibiotics ${ }^{1,2,3}$. Some of the problems that may arise from antibiotic misuse include therapeutic failure, increased patient's expense, unnecessary increase in the incidence of adverse drug reactions, and development of acquired multidrug resistance ${ }^{4,5,6}$ resulting in waste of resources and serious economic loss, with the developing nations being more affected due to the existing poverty ${ }^{1,7}$.

\begin{tabular}{|l|}
\hline *Corresponding author: \\
Titilayo O Fakeye \\
Department of Clinical Pharmacy \& Pharmacy \\
Administration \\
University of Ibadan \\
Nigeria \\
Tel: +2348052234484 \\
Email: titilayo.fakeye@yahoo.com \\
\hline
\end{tabular}

African Health Sciences Vol 13 Issue 4 December 2013
Factors contributing to antibiotic misuse are known to include use of antibiotics in animal husbandry ${ }^{8}$, unguided or misguided prophylactic use of antibiotics, and unnecessary extensive use of antibiotics which may be as a result of noncompliance or self-medication ${ }^{6,9}$. Antibiotics are ideally to be prescribed after due diligence has been done to ensure the sensitivity of the implicated microorganism(s) to the activity of the particular antimicrobial agent ${ }^{10}$. Studies evaluating misuse of antibiotics show that the misuse is neither dependent on education of the individuals involved nor the level of health care available in the country. Health professionals are also not exempted from the practice of recommending antibiotics for viral infections such as cold, upper respiratory tract infections or non-infective diarrhea ${ }^{11}$.

Previous studies showed that university undergraduate students are involved in misuse and abuse of various drugs ${ }^{7,12,13,14}$. However, in Nigeria, implementation of regulations governing the distribution, sales and use of antibiotics and other prescription medicines are weak, and sometimes 
non-existent ${ }^{15}$. As a result, the populace are at more risk of irrational use of drugs including antibiotics 2,7,12,14. The present study therefore evaluated the knowledge and attitude of non-medical undergraduate students of a university in the south-western Nigeria to antibiotics use.

\section{Methods}

\section{Study setting and Design}

This study was a prospective cross-sectional study carried out among non-medical undergraduate students of the University of Ibadan.. In this study, non-medical discipline of study was defined as undergraduate courses in faculties of Arts, Humanities, Education, Technology, Basic Sciences, Agriculture, Law and Social Sciences. Ethical principles outlined in the Helsinki declaration ${ }^{16}$ and as stated by the UI/UCH IRB was obtained and fully followed. At the time of the study in 2012, the total number of enrolled undergraduate students in all the faculties in the university was 11,823 . Using the Raosoft sample size calculator ${ }^{17}$ at a $5 \%$ margin of error, and 95\% confidence level, a sample size of 373 was obtained. This was round off to 400, and used as a guide to enroll eligible students between February and June, 2012.

\section{Validation and Pre-testing of questionnaire}

The 20-item questionnaire was assessed for content validity among three members of academic staff of the University of Ibadan, while the pretest was done among twenty students from the faculties of Arts and Education so as to ascertain the appropriateness of sampling procedure and ensure easy comprehension of the questionnaire. The twenty students were subsequently excluded from the main study. Based on the feedback from the pre-test and validity assessment, some questions especially those in open-ended format were re-modified in closeended format to eliminate response ambiguity. The pretested questionnaire was self-administered by the students.

\section{Inclusion/Exclusion criteria}

All undergraduate students (100-500 levels) from the forty-four departments in the non-medical faculties of Technology, Art, Law, Education, Basic Sciences, Social Sciences, and Agriculture were eligible and enrolled for the study based on the almost nonexistent exposure to medicine-related components of their curriculum. Postgraduate students of the university and undergraduate students from the Faculties of Pharmacy, Veterinary Medicine, and College of Medicine were excluded.

\section{Respondents sampling and data collection}

Classes to which the questionnaires were administered were randomly selected. The investigators

visited departments within the faculties of choice and lecture rooms where lectures had just finished distributing the questionnaire. A total of 400 questionnaires were administered through the class representatives using purposive sampling technique among consented students in each department after the selected classes had been briefed on the aims and objectives of the study. Participation was fully voluntary. The questionnaire was divided into sections: Section A clarified respondents' sociodemographic information, and section B contained questions that evaluated students' responses. Questions on respondents' knowledge of antibiotics and reasons for use, source of antibiotics used, disposal system for left-over antibiotics, if any, and the general belief about the use of antibiotics were asked. Other practices that may suggest antibiotic misuse were also explored.

\section{Data analysis}

The data obtained were analyzed using the Predictive Analytics Soft Ware (PASW) Version 17. Descriptive statistics including frequencies and percentages were used to summarize the data, while Chi Square was used to evaluate relationship between categorical variables with $\mathrm{p}<0.05$ considered significant.

\section{Results}

There were 145 (36.3\%) male and 255 (63.8\%) female respondents. Respondents were in the age range of 16 - 29 years. Pure science-based faculties comprising basic sciences, technology and agriculture had $151(37.8 \%)$ respondents while 249 (62.3\%) were from the humanities consisting of law, art, social sciences and education. Almost all the respondents (383; 95.8\%), had used antibiotics at different times.

The antibiotics were usually obtained on doctor's prescription $(273 ; 68.3 \%)$, pharmacist's recommendation $(44 ; 11.0 \%)$, nurse's recommendation $(24 ; 6.0 \%)$, trado-medical practitioner's recommendation $(5 ; 1.3 \%)$, selfmedication $(29 ; 7.3 \%)$ and from friends and relatives $(25 ; 6.3 \%)$. Frequency of use of antibiotics among respondents ranged from once a year $(10 ; 2.5 \%)$ to anytime the need arises e.g. when ill $(102 ; 25.5 \%)$, and anytime antibiotics are recommended (146; $36.5 \%$ ). Participants' knowledge of indications for antibiotics use is shown in table 1. Almost half the

African Health Sciences Vol 13 Issue 4 December 2013 
respondents $(168 ; 42.0 \%)$ always completed prescribed doses of antibiotics, while 114 (28.5\%) stopped taking antibiotics on the resolution of the symptoms. Seven respondents $(1.8 \%)$ sometimes changed to other antibiotics when the effect of the recommended/prescribed antibiotic was perceived not to be adequate. Eighty six respondents (21.5\%) stopped taking antibiotics without reason(s).

Table 1: Respondents' opinion on indication for antibiotic use

\begin{tabular}{llc}
\hline $\begin{array}{l}\text { Indications for use } \\
\text { of antibiotics(n=389) }\end{array}$ & Frequency & $\mathbf{\%}$ \\
\hline $\begin{array}{l}\text { Prevention of disease } \\
\text { from suspected intake }\end{array}$ & 200 & 51.41 \\
$\begin{array}{l}\text { of "bad water" } \\
\begin{array}{l}\text { Prevention of disease } \\
\text { from suspected intake }\end{array}\end{array}$ & 267 & 68.64 \\
$\begin{array}{l}\text { of "bad food" } \\
\text { Prevention of sexually }\end{array}$ & 299 & 76.86 \\
transmitted disease & & \\
$\begin{array}{l}\text { Headache } \\
\text { Catarrh }\end{array}$ & 100 & 25.71 \\
\end{tabular}

Response on what was done with unfinished doses of antibiotics showed that 187 (46.8\%) kept it for future use, $111(27.8 \%)$ threw it away with refuse, $30(7.5 \%)$ flushed it down the toilet while $25(6.3 \%)$ gave it to other people who may have similar complaints. Forty two $(10.5 \%)$ had simultaneously used more than one antibiotic including antibiotics with bactericidal and bacteriostatic properties (see table 2$)$, while three $(0.8 \%)$ reported taking proprietary antibacterial agents partly containing same generic contents e.g. Ampicillin with Ampiclox (R) (which contains ampicillin and cloxacillin). Some of the medications mentioned by the participants as examples of antibiotics were not antibiotics. Some were vitamins, such as Vitamins B complex and C, Tripolidine + Pseudoephedrine $\left(\right.$ Actifed $\left.{ }^{\mathrm{R}}\right)$, Folic acid, etc.

Table 2: List of "antibiotics" used simultaneously by respondents $(n=29)$

\begin{tabular}{|c|c|c|}
\hline Combinations of antibiotics used simultaneously & Frequency & $\%$ \\
\hline Vitamin C+Paracetamol+Procold ${ }^{* a}$ & 1 & 3.45 \\
\hline (Ampicillin + Cloxacillin $)+$ Amoxycillin $* *$ & 3 & 10.34 \\
\hline Ampicillin + Penicillin** & 1 & 3.45 \\
\hline Ampicillin $+(\text { Ampicillin }+ \text { Cloxacillin })^{* * *}$ & 3 & 10.34 \\
\hline Tetracycline + Amoxycillin**** & 2 & 6.90 \\
\hline Tetracycline + Folic Acid* & 3 & 10.34 \\
\hline Ciprofloxacin + (Ampicillin+Cloxacillin) $)^{* * * *}$ & 3 & 10.34 \\
\hline Cotrimoxazole $+(\text { Ampicillin }+ \text { Cloxacillin })^{* *}$ & 1 & 3.45 \\
\hline Nosclav $^{\mathrm{b}}+(\text { Ampicillin }+ \text { Cloxacillin })^{* *}$ & 1 & 3.45 \\
\hline Tetracycline + (Ampicillin+Cloxacillin)**** & 1 & 3.45 \\
\hline (Ampicillin+Cloxacillin) + Erythromycin** & 1 & 3.45 \\
\hline Artesunate + (Tripolidine + Pseudoephedrine $)^{*}$ & 1 & 3.45 \\
\hline Metronidazole + Tetracycline & 1 & 3.45 \\
\hline Amoxicillin + Ciprofloxacin $* * * *$ & 2 & 6.90 \\
\hline Vitamin B complex + Ferrous Sulphate* & 5 & 17.24 \\
\hline
\end{tabular}

* - One or both medicines are not antibiotics

$* *$ - Both medicines are antibiotics but there is no rationale for using them simultaneously

$* * *$ - One medicine partly contains one of the active ingredients of the other medicine

****- There may be antagonism i.e. bacteriostatic and bactericidal activities.

aprocold (Paracetamol + Phenylpropanolamine)

${ }^{\mathrm{b}}$ Nosclav (Ampicillin + Cloxacillin) 
Respondents $(127 ; 31.8 \%)$ who bought antibiotics without doctor's prescription used the antibiotics in different combinations for various ailments as shown in Table 3. Respondents who bought antibiotics without prescriptions used it for, in different combinations, $2-3$ days $(127 ; 100.0 \%), 4-5$ days (69; $54.3 \%),>5$ days $(35 ; 27.6 \%)$ and some, for not more than one day $(29 ; 22.8 \%)$. When symptoms were not resolved after taking antibiotics, $179(44.8 \%)$ go to the hospitals, $33(8.3 \%)$ complained to pharmacists, 14 (3.5\%) bought more antibiotics, while $11(2.8 \%)$ complained to nurses. Others, 9 $(2.3 \%)$ sought the advice of friends, $6(1.5 \%)$ changed to other antibiotics while $28(7.0 \%)$ took no further action.

Respondents (289; 72.3\%) did not take their antibiotics at the recommended time intervals. Some of the contributory reasons reported for such nonadherence behaviour included financial incapability to purchase full dose $(73 ; 18.3 \%)$, long duration of treatment $(70 ; 17.5 \%)$, side effects experienced $(60$; $15.0 \%)$, too many tablets to swallow $(56 ; 14.0 \%)$, tablets too large $(45 ; 11.3 \%)$ and low level of confidence in the prescriber $(11 ; 2.8 \%)$. A response common to the majority $(240 ; 60.0 \%)$ was that they forgot to go with their antibiotics whenever they travelled out of town. Some of the respondents (282; 70.5\%), in addition to the above reasons, also did not always remember the timing for administration of the medicines.

Penicillins were the most common antibiotics bought without prescription. These included Ampicillin+Cloxacillin (38; 29.9\%), followed by Amoxycillin (18; 14.2\%) and Ampicillin $(17 ; 13.4 \%)$.

There was no significant difference among respondents from the different courses of study with respect to knowledge of indications for antibiotics $(p=0.688)$. Also, there was no difference in their responses to the use, reasons for use and duration of use of antibiotics.

Table 3: Reasons given by respondents for purchasing antibiotics $(n=135)$

\begin{tabular}{lll}
\hline Reason for buying antibiotics & Frequency & $\mathbf{\%}$ \\
\hline Carbuncles (Boil)** & 28 & 20.74 \\
Unspecified Infection** & 25 & 18.52 \\
Malaria & 23 & 17.03 \\
Typhoid fever** & 7 & 5.19 \\
Stomach ache & 6 & 4.44 \\
Sore throat** & 6 & 4.44 \\
Diarrhoea* & 5 & 3.70 \\
Wound & 5 & 3.70 \\
Prevent sickness*** & 5 & 3.70 \\
Skin irritation*** & 5 & 3.70 \\
Pain*** & 3 & 2.22 \\
Feverish conditions & 3 & 2.22 \\
Menstrual pain*** & 2 & 1.48 \\
Constipation*** & 1 & 0.74 \\
Toilet infection**, Sexually transmitted disease**, Headache***, & 11 \\
Appetite stimulant***, Boost antibodies***, blood purification***, & 8.15 \\
repair of worn-out tissues*** & \\
* - Antibiotics may be indicated, however, only doctor should prescribe; \\
** - Antibiotics indicated but doctor should prescribe; \\
*** - Antibiotics not indicated.
\end{tabular}




\section{Discussion}

From the present study, a large number of respondents obtained antibiotics on doctor's prescription. Although, some of the respondents could be said to engage in irrational use of antibiotics, especially when there is no indication for its use, and at times, prematurely discontinued the antibiotics. Generally, the respondents' knowledge on what an antibiotic is, and the likely indications for antibiotic use were found to be grossly inadequate. Noninfectious ailments such as headache and catarrh were given as indications for which antibiotics were used. Also, vitamins, pain relievers, and cough and cold preparations containing pseudoephedrine + tripolidine were named as examples of antibiotics used. Previous studies have shown that inappropriate use of antibiotic in hospitals could be as high as 30 $-50 \%{ }^{18}$, and physicians are also involved in antibiotic abuse by prescribing inappropriate doses of antibiotics ${ }^{19}$.

The respondents' adherence to antibiotics was also found to be inadequate, since a large number of the respondents did not always complete the doses of antibiotics prescribed or purchased without prescription, while majority simply forgot the timing or forgot to take their medicines along with them while travelling. The wrong indications for antibiotic use and non-completion of prescribed or recommended doses could encourage a faster development of resistance to specific antibiotics.

Literature confirms that the use of antibiotics for empirical therapy without definitive laboratory confirmation of the implicated organism could increase the likelihood of development of resistant strains $20,21,22,23,24$. It is of interest to note that most of the antibiotics used by the respondents were penicillins which are â-lactamase sensitive with established resistance profile ${ }^{25,26}$. The resistance profile of penicillins generally is poor in the locality where the study was carried out ${ }^{27,28,29}$ and as reported in a study conducted in Cape Coast in Ghana ${ }^{30,31}$. It is safe to say that this kind of practice found with the respondents in this study might be a contributory factor to the rising rates of resistance to antibiotics. The responses to what is done to the left-over antibiotics are revealing. However, the case of leftover antibiotics shows that either the quantity purchased by individual, or the doses of antibiotic prescribed by an authorised healthcare provider is more than the required dose, or that the regimen was stopped without completing the prescribed doses. This is a further justification suggesting the need for a definitive laboratory confirmation in order to determine the implicated microorganism thereby ensuring the appropriate treatment duration or regimen. Methods of disposal of left-over antibiotics are also not suitable. The act of flushing this class of drugs down the toilet, or throwing it away with refuse may also encourage resistance to these antibiotics of some of the pathogens that may be found in the sewage. Two separate studies have documented that these methods of disposal of antibiotics do not only lead to the development of multidrug resistant strains of pathogens but also can negatively impact on the environment and cause serious health risk ${ }^{31,32}$. In the study by Mispagel \& Gary ${ }^{32}$, there was a high number of antibiotic resistant bacteria from pond discharges which was linked to flushing unused antibiotic medications down the toilet by residents.

The act of keeping remaining antibiotics for future use or giving the remaining antibiotics to other people who may have similar ailments is not a safe practice and should be discouraged. In general, there may be need to enlighten the populace about the proper disposal of any unused medicines preferably by encouraging the management of the hospitals and the communities to institute a Disposal of Unused Medicines Programme (DUMP).

The simultaneous use of two or more antibiotics is a practice that is usually discouraged except in selected cases when synergism is required. The use of antibiotics with bactericidal versus bacteriostatic properties is discouraged probably due to antagonism of activity or sometimes, the effects of the bactericidal activity may be nullified by the bacteriostatic antibiotics.

This study was however limited by fact that respondents were not asked to indicate the particular antibiotic they had used for particular ailments. This would have helped in addressing the issue of the implicated antibiotics commonly used for wrong indications. Notwithstanding, future study may need to comprehensively look into this aspect.

\section{Conclusion}

Misuse of antibiotics among non-medical undergraduate students in a Nigerian university setting is pervasive. The students' engagement in different acts of misuse and non-adherence practices with the antibiotics further underscore the urgent need for improved health education and enlightenment 
campaigns among university students generally on rationale antibiotic usage, and the consequence of irrational use. This can possibly be achieved either by incorporating health-related topics focusing on rational use of antibiotics in the general courses which are compulsory courses for every student, and which gives general knowledge to the students outside their area of study. Also, primary healthcare providers in educational institutions should continue to encourage students to engage in prudent use of antibiotics while Disposal of Unused Medicines Programme should be instituted in university communities.

\section{References}

1. Wolff J, Marcelo. Use and Misuse of Antibiotics in Latin America. Clinical Infectious Diseases 1993; 17 (2): S346-S351.

2. Bojalil R, Calva J. Antibiotic misuse in diarrhea. A household survey in a Mexican community. Journal of Clinical Epidemiology 1994; 47 (2): 147156.

3. Peche're JC. Patients' Interviews and Misuse of Antibiotics, Clinical Infectious Diseases 2001; 33 (3): S170-S173.

4. Bilal NE, Gedebou M, Al-Ghamdi S. Endemic nosocomial infections and misuse of antibiotics in a maternity hospital in Saudi Arabia. Acta Pathologica Microbiologica et Immunologica Scandinavica 2002; 110 (2): 140-147

5. Al-Ghamdi S, Gedebou M, Bilal NE. Nosocomial infections and misuse of antibiotics in a provincial community hospital, Saudi Arabia, Journal of Hospital Infection 2002; 50 (2): 115-121.

6. Carey B, Cryan B. Antibiotic misuse in the community-a contributor to resistance? Irish Medical Journal 2003, 96 (2): 43-46.

7. Buke C,Hosgor-Limoncu M, Ermertcan S, Ciceklioglu M, Tuncel M, Köse T et al. Irrational use of antibiotics among university students. Journal of Infection 2005; 51 (2): 135-139.

8. Khachatourians GG. Agricultural use of antibiotics and the evolution and transfer of antibiotic-resistant bacteria. Canadian Medical Association Journal 1998; 159: 1129-1136.

9. Maki DG, Schuna AA. A study of antimicrobial misuse in a university hospital. The American Journal of the Medical Sciences 1978; 275 (3): 271282.

10. Dunagan WC, Woodward RS, Medoff G, Gray JL, Casabar E, Lawrenz C, et al. Antibiotic Misuse in Two Clinical Situations:
Positive Blood Culture and Administration of Aminoglycosides. Clinical Infectious Diseases 1991; 13 (3): 405-412. doi: 10.1093/ clinids/13.3.405

11. Fakeye TO, Omotayo S, Adisa R. Knowledge and treatment recommendations of community pharmacists for cases of diarrhea, migraine headache and malaria in a metropolitan city in southwestern Nigeria. International Journal of Pharmacy Practice. 2013; 21; Suppl (1): 39-40

12. Fakeye TO, Itiola OA, \& Aboderin O. (1998). Attitude of University of Ibadan students to antibiotic usage. Nigerian Journal of Pharmacy 1998; 29 (4): 205-207.

13. Istúriz, RE, Carbon C. Antibiotic Use in Developing Countries. Infection Control and Hospital Epidemiology 2000; 21 (6): 394-397. doi:10.1086/501780.

14. Mitema ES. The Role of Unregulated Sale and Dispensing of Antimicrobial Agents on the Development of Antimicrobial Resistance in Developing Countries." In Antimicrobial Resistance in Developing Countries, ed. Aníbal de J. Sosa, Denis K. Byarugaba, Carlos F. Amábile-Cuevas, Po-Ren Hsueh, Samuel Kariuki, and Iruka N. Okeke, 2010. 403-411. Springer New York.

15. Erhun WO, Babalola OO, Erhun MO. Drug Regulation and Control in Nigeria: The Challenge of Counterfeit Drugs. Journal of Health \& Population in Developing Countries 2001; 4 (2): 23-34

16. Williams JR. The Declaration of Helsinki and public health. Bulletin of World Health Organization. 2008; 86(8): 650-652

17. Raosoft Sample Size Calculator http:// www.raosoft.com/samplesize.html (Accessed on the $15^{\text {th }}$ January, 2012).

18. Harrison JW, Svec TA. The Beginning of the End of the Antibiotic Era? Part II. Proposed Solutions to Antibiotic Abuse. Quintessence International. 1998; 29 (4) : 223-229.

19. Amidi S, Steven S, Bagher R, Ali-Reza Z, Razmjoian. Antibiotic use and abuse among physicians in private practice in Shiraz, Iran. Medical Care 2013; 51: 341-345

20. Seppälä H, Klaukka T, Vuopio-Varkila J, Muotiala A, Helenius H, Lager K, et al. The Effect of Changes in the Consumption of Macrolide Antibiotics on Erythromycin Resistance in Group A Streptococci in Finland. 
New England Journal of Medicine 1997; 337: 441446

21. Okeke IN, Lamikanra A, Edelman R. Socioeconomic and Behavioral Factors Leading to Acquired Bacterial Resistance to Antibiotics in Developing Countries. Emerging Infectious Diseases 1999; 5 (1): 18-27.

22. Amabile-Cuevas C. Antibiotic Resistance in Mexico: a Brief Overview of the Current Status and Its Causes. The Journal of Infection in Developing Countries 2010; 4 (03): doi:10.3855/ jidc. 427.

23. English BK, and Aditya HG. The Use and Abuse of Antibiotics and the Development of Antibiotic Resistance." In Hot Topics in Infection and Immunity in Children VI, ed. Adam Finn, Nigel Curtis, and Andrew J. Pollard, 73-82. Advances in Experimental Medicine and Biology. 2010. 659. Springer New York. http:/ /link.springer.com/chapter/10.1007/978-14419-0981-7_6.

24. Levy SB. Antibiotic Resistance: Consequences of Inaction. Clinical Infectious Diseases 2001; 33 (s3): S124-S129.

25. Frère JM. Beta-lactamases and Bacterial Resistance to Antibiotics. Molecular Microbiology 1995; 16 (3): 385-395.

26. Sinha M, Srinivasa H, Macaden R. Antibiotic resistance profile and extended spectrum betalactamase (ESBL) production in Acinetobacter species. The Indian Journal of Medical Research 2007: 126 (1): 63-67.
27. Osoba AO, Montefiore DG, Sogbetun AO, Alausa KO, Anong CN. Sensitivity Pattern of Neisseria Gonorrhoeae to Penicillin and Screening for â-lactamase Production in Ibadan, Nigeria. The British Journal of Venereal Diseases 1977; 53 (5): 304-307.

28. Montefiore D, Rotimi VO, Adeyemi-Doro FB. The Problem of Bacterial Resistance to Antibiotics Among Strains Isolated from Hospital Patients in Lagos and Ibadan, Nigeria. Journal of Antimicrobial Chemotherapy 1989; 23 (4): 641-651.

29. Ghebremedhin B, Olugbosi MO, Raji AM, Layer F, Bakare RA, Köni B, König W. Emergence of a Community-Associated Methicillin-Resistant Staphylococcus Aureus Strain with a Unique Resistance Profile in Southwest Nigeria. Journal of Clinical Microbiology 2009; 47 (9): 2975-2980.

30. Tagoe, DNA, Attah CO. A Study of Antibiotic Use and Abuse in Ghana: a Case Study of the Cape Coast Metropolis. The Internet Journal of Health 2010; 11 (2). doi:10.5580/bec.

31. Sasu S, Klaus K, Martin K. Assessment of Pharmaceutical Waste Management at Selected Hospitals and Homes in Ghana. Waste Management \& Research 2012; 30 (6): 625-630.

32. Mispagel H, Jeffrey T Gy. Antibiotic Resistance from Wastewater Oxidation Ponds. Water Environment Research 2005; 77 (7): 2996-3002. 